\title{
Library leadership: Innovative options for designing training programmes to build leadership competencies in the digital age
}

\author{
Ann-Louise de Boer ${ }^{1}$, Theo J.D. Bothma ${ }^{2}$ and Johan Olwagen ${ }^{3}$ \\ Department of Information Science, University of Pretoria \\ ann-louise.deboer@up.ac.za; theo.bothma@up.ac.za; olliej@mweb.co.za
}

Received 22 May 2012

Accepted 5 July 2012

\begin{abstract}
Library leaders may not be fully equipped to deal with the demands and rigours of the digital age and its consumers. The advent of the internet, search engines and social media require a paradigm shift in the development of these leaders. Whilst much has been written about the required competencies, there seems to be no clear guiding principle on how the development should take place. The authors propose that the development of library leaders is a process, best illustrated through movement through Drotter's Leadership Pipeline. The importance of thinking preferences, based on Herrmann's Whole Brain Model, is highlighted and it is shown how these often clog development through this Pipeline. Utilising data from the Herrmann Brain Dominance Instrument (HBDI) assessments of the 120 participants in six of the Centre for African Library Leadership (CALL) development programmes, the authors show how the thinking preferences of these library leaders could enable or detract from their readiness to develop the appropriate competencies in the digital age. Recommendations are made on how best to overcome this to prepare library leaders to deal with the requirements of the digital age consumer.
\end{abstract}

Keywords: Library leadership, Herrmann’s Whole Brain Model ${ }^{\circledR}$, Drotter’s Leadership Pipeline, training programmes, Centre for African Library Leadership

\section{Introduction}

The competence and effectiveness of library leadership, particularly in Africa, have been in the spotlight for a number of years. Several reasons ranging from personal competence to environmental factors have been mooted as to why library leaders are not as effective as they should be.

A grant from the Carnegie Corporation of New York was made available to the Department of Library Services (UPLS) at the University of Pretoria to establish the Centre for African Library Leadership (CALL) at the UPLS and design a Library Leadership programme (Carnegie Library Leadership Academy, CLLA) aimed at addressing some of the prevalent issues (UPLS 2008). The CLLA programme (presented at what became known as 'Academies') is designed to give librarians the opportunity to meet colleagues as well as senior professionals from different backgrounds, provinces and institutions and so initiate a paradigm shift for leading the profession. The programme covered theoretical as well as practical aspects, including organisational leadership and behaviour; innovation and change management; leadership descriptor tools (such as the Campbell Leadership Descriptor and the Herrmann Brain Dominance Instrument ${ }^{\circledR}$ ); multiculturalism and diversity in the workplace; organisational ethics; knowledge management; effective communication; advocacy; branding and marketing, and Web 2.0 and mobile technologies. The programme was contextualised through lectures about the position of libraries on the national and international agendas, as well as through lectures about nextgeneration librarians. Two assignments formed part of the formative evaluation, while students also had to do a formal research assignment under the supervision of a mentor (senior staff members from library and information science departments at three South African universities). The first intake of 20 participants was in July 2009 and the last in April 20I2. A total of I 20 participants attended the six Academies over the three-year period.

Although there exists a considerable body of research literature on traits and competencies of library leaders (as well as external factors influencing library leaders), we have not found any research on linking competencies, thinking preferences and leadership requirements of library leaders in the digital age.

The purpose of our research is to report on the thinking preferences of future library leaders in South Africa (as evidenced by the six Academies) and to link the results to the identified leadership traits and to leadership positions. Our

I. Ann-Louise de Boer (PhD) is an associate professor in the Department of Information Science, University of Pretoria, South Africa.

2. Theo Bothma (DLitt \& Phil) is professor and Head of Department of the Department of Information Science, University of Pretoria, South Africa.

3. Johan Olwagen is an independent consultant and visiting researcher in the Department of Information Science, University of Pretoria, South Africa. 
ultimate aim is to propose innovative options for consideration in designing a leadership training programme, and hence to build on much needed competencies suitable for the digital age.

In order to make the link between thinking preferences and thinking requirements of leadership positions we reconceptualise the Leadership Pipeline of Drotter (2003) through the lens of the Whole Brain Model ${ }^{\circledR}$ (Herrmann I995, 1996). This article will highlight how inappropriate thinking at a leadership level could clog the pipeline and derail future library leaders from doing what is appropriate at each level of the Leadership Pipeline. The authors will show how the focus at each level of the pipeline needs to shift between the quadrants of the Whole Brain ${ }^{\circledR}$ model to successfully traverse the pipeline and move from being specialists to becoming leaders in the $21^{\text {st }}$ century.

\section{Research questions}

The following research questions will be addressed:

- What are the thinking preferences of the future library leaders in South Africa?

- What are the thinking requirements of the various leadership positions?

- How can we link thinking preferences and thinking requirements to leadership traits?

- What innovative options can be built into a Library leadership development programme to develop thinking requirements for the digital age?

\section{Literature review}

\subsection{Library leadership competencies}

Management is about organising the functions that need to be done, while leadership is about empowering, inspiring and mentoring. It is leadership that determines whether philosophy and vision are articulated and to what extent they are implemented.

Ammons-Stephens et al., (2009) investigated various leadership competency models and on the basis of this investigation and empirical research compiled a list of core competencies for library leaders. They went along with the views of Kurz and Bartram (2002) in distinguishing between competence and competencies (Ammons-Stephens et al., 2009: 63):

Kurz and Bartram are very precise in their effort to distinguish between competence and competency: Competence is about mastery in relation to specified goals or outcomes. The measurement of competence at work involves the assessment of performance in the workplace against some pre-defined set of occupational or work-related standards or requirements. Competencies, on the other hand, relate to the behaviours underpinning successful performance; what it is people do in order to meet their objectives; how they go about achieving the required outcomes; what enables their competent performance.

Ammons-Stephens, Cole, Jenkins-Gibbs, Riehle and Weare (2009) also reported that although research exists on the competencies needed by practitioners in various areas of librarianship, very little literature is found on addressing these competencies. They (Ammons-Stephens et al., 2009: 65) listed six areas of attributes, namely "leadership, planning, abilities, skills, individual traits, and areas of knowledge" based on the article by Hernon, Powell and Young (200I). These attributes are all in alignment with leadership research for other professions. In a second article, Hernon, Powell and Young (2002) "identified and categorized present and future attributes of prospective directors" (Ammons-Stephens et al,. 2009: 65). The attributes were grouped under three major headings:

- Managerial attributes, which include managing, leading and planning;

- Personal characteristics, which include dealing with others, general individual traits and individual traits pertaining to leadership;

- General areas of knowledge.

In expanding on their research, Hernon, Powell and Young (2003) provided a comprehensive assessment of effective leadership identifying traits needed by the next generation of academic and public library directors. Ammons-Stephens et al. (2009: 65) mention that individual chapters in Hernon and Rossiter (2007) discuss competencies applicable to library leadership as including interpersonal and communications skills, the ability to evaluate data and use such data for decision making, and a focus on softer skills such as emotional intelligence (see also Hernon and Rossiter 2006).

Ammons-Stephens et al., (2009: 68-7I) designed a Core Leadership Competency Model which includes four central leadership competencies for library leadership, namely cognitive ability, vision, interpersonal effectiveness and managerial

SA Jnl Libs \& Info Sci 2012, 78(2) 
effectiveness, each encompassing a number of 'broad competencies':

- Cognitive ability, higher-order thinking skills include "creative thinking, critical, and analytical thinking, data manipulation, synthesis and decision making" (Ammons-Stephens et al., 2009: 68).

- Vision includes the ability "to think globally, think creativity [sic] and foster innovation, as well as the ability to be forward-thinking" (Ammons-Stephens et al., 2009: 69).

- Interpersonal effectiveness, "describing leaders who can create a positive atmosphere centred on respect, responsibility, and motivation" (Ammons-Stephens et al., 2009: 69).

- Managerial effectiveness, which includes the ability "to manage change, manage resources, plan for the future, collaborate with others and have the ability to be flexible" (Ammons-Stephens et al., 2009: 70).

In another comprehensive study on the components of emotional intelligence conducted by Hopper (2005), she analysed five books on leadership traits. The tabulated and categorised traits reported by Hernon and Rossiter (2006) were used as a point of departure for the analyses (the Hernon and Rossiter publication was 'in press' at the time of Hopper's 2005 study). The content of the five books were analysed and each of the traits of Hernon and Rossiter (2006) was counted each time it was referred to as a desirable trait in a library leader. (Additional traits not listed in Hernon and Rossiter (2006) were also identified.) The five main categories that both studies used are self-awareness, self-regulation, motivation, empathy and social skill.

In comparing her data with those of Hernon and Rossiter (2006), Hopper (2005: 17) indicates that the results reveal that the trait most mentioned from the total of 96 traits was being visionary (listed in the category Motivation). Hopper quotes from Riggs (1998): "The challenge is to become skilled in the 'art of seeing' and in the 'art of reading' the future of libraries. Dreams, ideas, and even metaphors may be helpful in developing the mental model of the $21^{\text {st }}$ century library" (Hopper 2005: 15). Vision, innovation and technology are important aspects for the digital age because we are able to 'see' and 'read' the future demands of where libraries are going. With this knowledge we can then proactively implement innovative technology options for the digital age. Another 'vision-related' trait that was very highly rated was the ability to articulate direction for the library (Hopper 2005: 16).

The second most valued trait was the ability to motivate people (also in the category Motivation). To inspire people to a shared vision is a conscious decision of people in leadership positions. Natural leaders who inspire others create followers and ensure that the company/institution moves ahead.

Both studies are in agreement that a highly valued trait (and the most highly valued trait in Self-Regulation) is to be flexible and comfortable with change (Hopper 2005: 12). This implies actually anticipating change, especially in the digital age in which we find ourselves today. Lynch (1988: 77) writes:

Clearly what is before us is the realisation that we must know and learn as much as we can about the present and future technologies so as to participate in a meaningful way in the necessary decision-making regarding our libraries and the services they provide.

Riggs (200I: 10) puts it in another way:

Managing change is not good enough. We must anticipate, plan, and lead change. With the impact of the evolving library technology, some librarians who have been successful in the past may not be successful in the future if they continue doing things they have been doing in the past. They will have to talk with different people, listen to different people, and in a sense they will have to unlearn those activities that brought them success in the past.

The ability to be visionary, to embrace change and to anticipate future information technologies, thereby providing strategic direction for their libraries and the ability to motivate their colleagues to share the vision, will empower library leaders for the digital demands of the $21^{\text {st }}$ century.

\subsection{Herrmann's Whole Brain ${ }^{\circledR}$ model}

The Herrmann Brain Dominance Instrument ${ }^{\circledR}$ is an assessment tool that quantifies the degree of a person's preference for specific thinking modes, i.e. how we prefer to think, learn, understand and express ourselves (Herrmann 1995: 17).

Herrmann describes the Whole Brain ${ }^{\circledR}$ model as a metaphoric model since the operation of the brain is immeasurably more complex and versatile than the simple dichotic model implies (Herrmann 1995:64). The four-quadrant metaphoric model and profile describes how a person prefers to acquire and process information, not how fast or accurately he/she 
does it (Herrmann 1995:70). The concept of applied Whole Brain ${ }^{\circledR}$ thinking is based on our application of these specialised modes shown in Figurel.

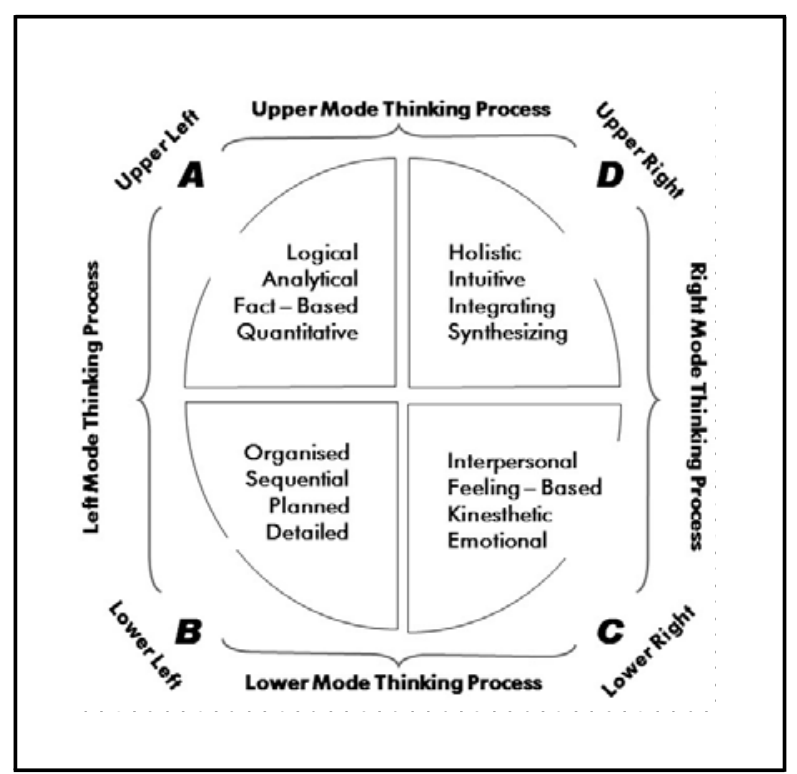

Figure 1 Herrmann’s Whole Brain ${ }^{\circledR}$ model

A preference for the A-quadrant (upper left mode) indicates that a person favours activities that involve logical, rational, analytical and fact-based information (Herrmann 1996: 104). Such individuals are focused on the task at hand. They typically incline toward the information side of the job. They are content to work on problems and their focus and energy are directed at solving the problem based on facts. They prefer to work with sophisticated technology and apply it in the workplace to be more effective. On the other hand, they have a lower preference for vague, imprecise concepts or ideas, a lack of logic and expressing emotions, and when they interact with others, they are more concerned with the process of analysing and defining facts and debates around best equipment, methodology and products than with people. Figure 2 is a typical example of A-quadrant thinking preference.

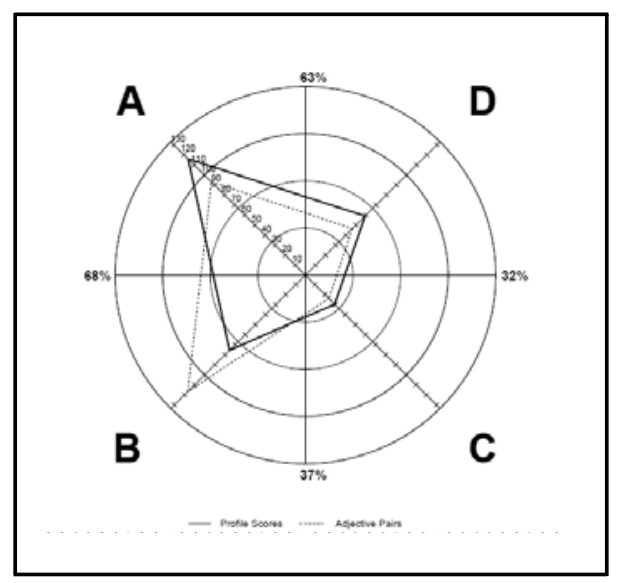

Figure 2 An example of a profile indicating A-quadrant thinking preference

The B-quadrant thinking preferences (left lower mode) typically exhibit a highly traditional and conservative approach. Such individuals feel comfortable in an environment that is predictable, stable and safe; therefore they tend to resist change. Accountability is important and they want to follow set guidelines, look at detail, stick to strict plans and rules. Individuals with a B-quadrant preference favour organised, sequentially planned and detailed information and they have a low preference for unclear concepts or instructions (Herrmann 1996: 105). Figure 3 is an example of B-quadrant thinking preference. 


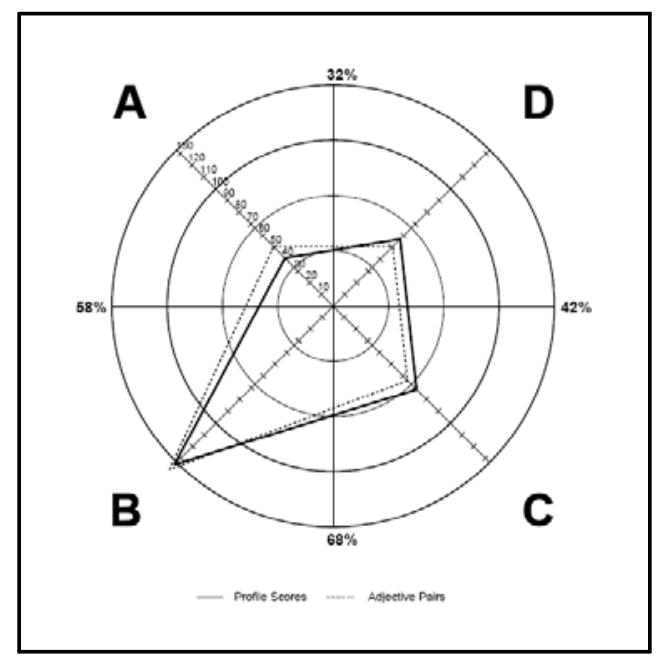

Figure 3 An example of a profile indicating Bquadrant thinking preference

The C-quadrant thinking preferences (the lower right mode) feel comfortable with face-to-face engagement in solving problems. Interpersonal information and employees' relationship with the organisation are important to them. They feel strongly about employee development, on-site training, and taking into account the safety of the workers at all times. They are people-focused individuals. A high priority is placed on effective employee communication. These individuals may have a low preference for too much data and analysis, over-use of technology, and too much detail (Herrmann 1996: 106). Figure 4 is an example of $C$-quadrant thinking preference.

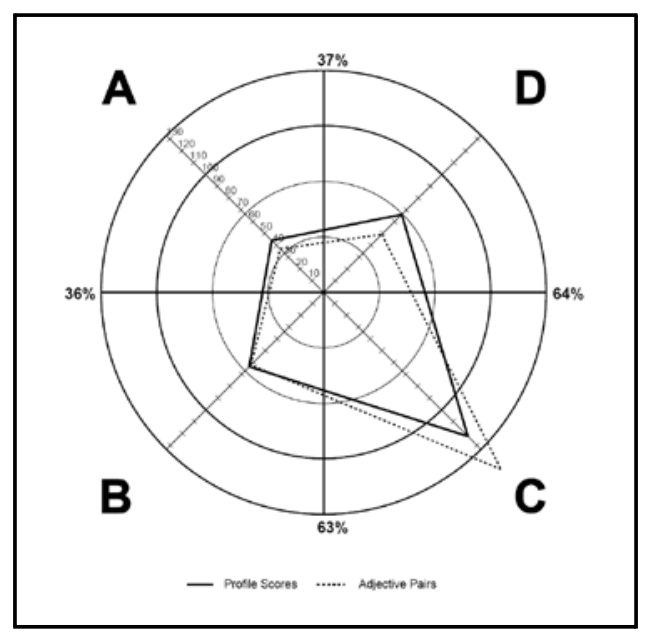

Figure 4 An example of a profile indicating Cquadrant thinking preference

D-quadrant thinking (the upper right mode) is often described as the style of the entrepreneur. These individuals favour holistic, conceptual, imaginative and integrative mental processes. Managers with this type of thinking preference often display independence and therefore prefer a flexible environment. They need time and space for thinking and thrive under a system of trust to deliver the work on time. They are individuals who are often described as adventurous, taking risks and visionary thinkers. With their ability to think strategically, they are able to think far into the future. They have a low preference for overtly strict time management, lack of flexibility and too much detail (Herrmann 1996: 107). Figure 5 is an example of $\mathrm{D}$-quadrant thinking preference. 


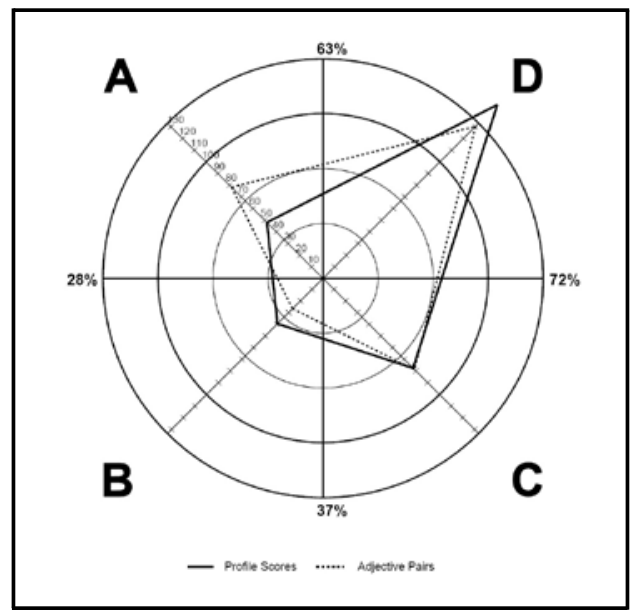

Figure 5 An example of a profile indicating Dquadrant thinking preference

Herrmann (1996) concludes that, although an individual may favour cognitive activities associated with a specific quadrant, there is an equal distribution of preferences of individuals across the four quadrants. Furthermore, both left and right and upper and lower modes contribute to everything, but they contribute to a different degree. Although each quadrant is different, they are all equal in importance. In fact, no person is linked to a single perspective - we are indeed hard-wired to be whole, based on the principle that we all have a whole brain.

\subsection{Drotter's Leadership Pipeline model}

According to Drotter (2003: 4), one of the major problems experienced by newly promoted leaders is that they find it difficult to let go of habits that were responsible for getting them promoted. They often cling to thinking, behaviours, attitudes and skills that made them successful in the past. Drotter argues that managers accept a promotion to a higher level in an organisation without accepting the thinking requirements, behaviour, attitudes and skills of the new position. Leaders are not even made aware of the fact that their thinking skills could be inappropriate.

Drotter's concept of a Leadership Pipeline comprises a basic level of ability and self-knowledge (managing self) that is followed by six higher levels of leadership functions. Each level requires new responsibilities, competencies and thinking requirements. The focus of the Leadership Pipeline model is to grow leadership talent within an organisation. When organisations want to develop a leader's talent, the individual much too often gets promoted based only on his/her high technical ability. The specific thinking requirements needed by the individual to excel at the level promoted to are often overlooked (Charan et al., 200I: 16). Organisations need to also ask the question whether the promoted manager can adapt to the thinking processes required by the level concerned. If the answer is no, it implies that the individual cannot or does not understand that different thinking skills are required. Charan et al., (200I:9) argue that the pipeline then gets clogged and positions operate at a lower level, which affects the whole organisation. 


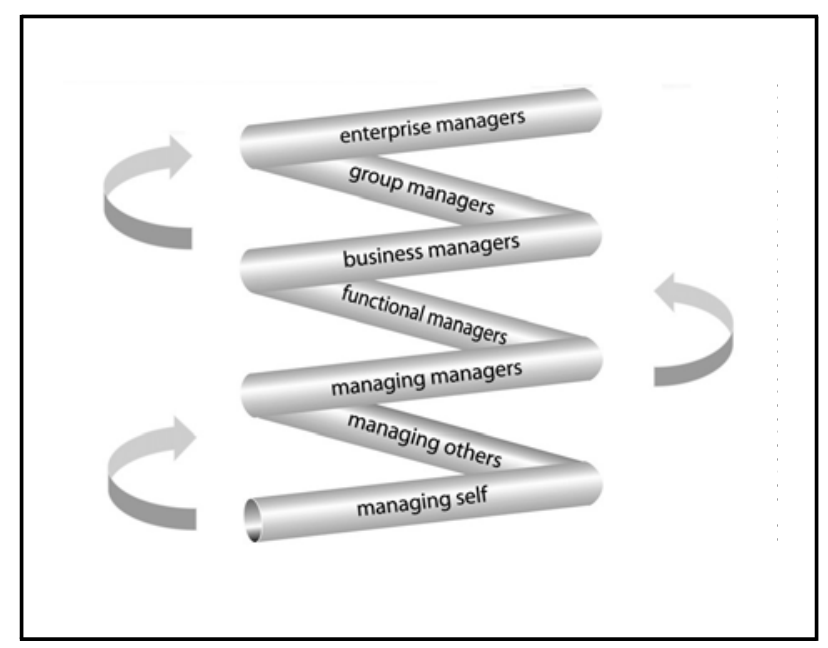

Figure 6 The management levels of Drotter's (2003)

Leadership Pipeline model

Success in managing oneself constitutes the basis for moving on to the next level, but it is not sufficient to manage others, or to manage managers. New insights and new skills need to be developed before one can become successful at each of the next levels. The thinking requirements of each level will be described next.

\subsection{The Leadership Pipeline Model: Managing Self}

Young professionals start their careers with an organisation or institution as individuals who contribute their skills and knowledge. The primary goal is to deliver technical or professional skills aimed at getting the job done. Contribution on this level is when the individual adopts a professional standard, meets or exceeds the objectives set, and produces excellent results within the given time frames.

On this level, movement to the next level can be achieved by mastering the art of motivating and managing oneself. Self-management implies moving from being someone who is told what to do, to becoming a self-motivated individual who engages with his/her own brain. The most important proficiency during this phase involves sharpening individual skills and collaborating with others. If this is done well, individuals become promotable.

\subsubsection{The Leadership Pipeline Model: Managing Others}

Newly promoted managers often accept their new role without also accepting the thinking requirements of the position. Most of the time individuals want to keep doing activities that made them successful in the first place, i.e. displaying their technical skills (Drotter 2003: 33). They often keep competing, completing the work assigned to others and getting frustrated by how others then approach the job. The requirements of the position are, however, to let go of some of their technical expertise and get the job done through others.

Managers can no longer spend most of their time on fire fighting, so to speak. Subordinates need to complete their tasks on their own. The problem, however, occurs when the newly appointed manager has to give up tasks and responsibilities that he/she prefers to do - tasks that earned him/her a manager's title in the first place. It becomes tremendously difficult to let go.

The main focus of the new manager should be on effective communication to facilitate open dialogue, i.e. communicating clear expectations to direct subordinates; assisting them in planning and organising the workload; delegating tasks to others. This will require enabling direct subordinates to do the work; setting goals for others to achieve; monitoring and measuring outputs; coaching for performance; providing feedback on performance and gaps in the performance; solving problems; motivating staff through engagement; providing support and building trusting relationships.

\subsubsection{The Leadership Pipeline Model: Managing Managers}

Charan et al., (200I: 18) points out that this stage is frequently ignored and only few organisations provide efficient training to support the manager who operates at this level.

The biggest challenge during this phase is management itself. Individual contribution was part of the management function when these individuals managed others and yet an emphasis on individual contribution no longer adds value at 
this function level (Charan et al., 200I: 19). Now leaders need to be able to think beyond the function, they need to concern themselves with tactical and strategic issues that will support the overall business.

The manager who manages other managers has to think more broadly than just the individual silos. He/she needs to integrate the work in a more holistic manner, think of how to achieve best practices and ensure that the work flow is streamlined across teams. Where difficulties are experienced, problems need to be solved with these managers and through their teams. The manager should not personally suggest all the solutions, as this might dis-empower managers and people further down the pipeline. Instead, he/she needs to coach potential leaders from lower levels of the leadership pipeline and assign managerial tasks to them. They should be monitored and coached to enable them to fulfil their main task, namely the development of leadership in the organisation. In addition, they need to begin engaging with other stakeholders and work contextually. They need to ensure operational effectiveness in implementing the business strategy.

If leaders find it difficult on this level to divert from individual contribution to functional work (and they still value individual contributions more), they help maintain the wrong values in individuals who report to them. Charan et al. (200I: 52) point out that this is often the case where the managers of managers skip first-line management through promotion and have not yet made the thinking transitions required for the previous levels. They now clog the leadership pipeline because they hold first-line managers accountable for technical rather than managerial work. All start functioning at a level below their appointment, because they themselves skipped that phase and they still value individual contributions above managerial ones. Charan et al. (2001:9) go so far as to say "[t]hey poison the managerial well" in this way because they instil the wrong values in those individuals who report to them. They choose high technical achievers for first-line managerial posts rather than true potential leaders, because they are unable to differentiate between those who can do and those who can lead. Through their own action, they then become obstacles within the leadership pipeline model - no matter how brilliant.

The manager who can make this thinking shift, can easily identify the high flyer that will get no job satisfaction from managing and leading people, but wants to remain a specialist. The manager should create a growth path for such individuals within the organisation. If not, the organisation stands the chance of losing talented people, as not all people want to or have the natural ability to effectively lead other people.

\subsubsection{The Leadership Pipeline Model: Managing the Function}

Charan et al. (200I: 66) acknowledge the fact that making the transition from managing managers to managing the function is tougher than it seems. They admit that it requires increased leadership maturity to be successful, because it is a big promotion.

Functional managers must learn to value, develop necessary skills and spend time on functional strategy and managing the whole function (Charan et al., 2001: 70).

Usually the mature leader has developed thinking skills such as empathy, listening, judgement and eliciting information from all avenues. It is now time to let go of the old silo behaviours and thinking, and to embrace the integrated thinking of the total business philosophy (Charan et al. 200I: 79).

Communication becomes a more complex process. Communication with individual contributors needs to penetrate at least two layers of management - this means the leader will need to have or develop communication skills that represent all four quadrants of the Whole Brain ${ }^{\circledR}$ model (see Figure I). Communication takes place in multiple layers that extend geographically and often horizontally and vertically. The shift in communication skills should be away from talking to active listening.

Another challenge involves being able to manage areas that are outside of your own expertise; hence, understanding jobs of other functions within the business is essential. Reporting takes place to multifunctional general managers and they have to become knowledgeable about and skilful at taking other functional concerns and needs into consideration during the problem-solving and decision-making processes. They need to be able to focus on both short and long term strategy, and to integrate different functions within the overall business goals. They have to be futuristic and systemic thinkers who can create a functional strategy that enables the company to do better than the competition. They have to think about innovative products, or how to reach more customers in the future and sustain a competitive advantage.

\subsubsection{The Leadership Pipeline Model: Managing the Business}

The biggest challenge in shifting the thinking of managers on all the levels of the Leadership Pipeline lies here, and it should not be underestimated. It involves letting go of the functional mind set. To quote Charan et al. (200I): 
It's not simply a question of learning new skills or reallocating one's time. Business managers actually have to change the way they think.

Given the complexity of thinking preferences required at this level, a shift from appropriately valuing one's own function to appropriately valuing all functions becomes critical. The individual needs to integrate functional networking by building business strategy and focusing on what can be done and how to get it done. The business manager has to operate conceptually and at the same time make connections for the short and long term.

Working cross-functionally requires from managers to look at the business from all angles, including its profitability and sustainability - from a technical, professional and physical perspective. Managers cannot become more strategic and cross-functional in their thinking overnight. These skills need to be developed over a period of time: the growing of talent needs to take place progressively at lower levels, using intensive coaching.

Leaders who have successfully passed through the leadership pipeline and adapted to the new thinking requirements that each level requires, usually finds this level (managing the business) very rewarding and satisfying because they experience autonomy and freedom. They are able to see the link between their efforts and the results they achieve (Charan et al. 200I: 8I). However, if they did not pass through the pipeline or if they skipped a level or two, they find it very difficult at this level and, under stress, often revert to their old mental model (Charan et al. 200I: 84).

\subsubsection{The Leadership Pipeline Model: Managing the Group}

Drotter (in Charan et al. 200I: 99) points out the flaws in the assumption and reasoning that running one business successfully (managing the business) will enable one to run multiple business units successfully (i.e. managing the group). The flaw is that a business manager focuses on the success of the business he/she has been appointed to. A group manager, on the other hand, needs to focus on all of the other businesses as well. Therefore different thinking is required. The position is more of a nurturing and hands-off role. Managing the group often requires from an individual to give up work he/she enjoys. Moreover, this position often is a test for the role of a possible group CEO (Charan et al. 200I: I02).

The group manager needs to be able to shift, balance and integrate thinking preferences in order to be successful. He/ she must have knowledge, analytical skills, personal credibility and good relationship skills to make a success of the position (Charan et al. 200I: 106). Some critical thinking skills involve the need to evaluate strategy mainly for capital allocation and deployment purposes, as well as the ability to analyse and interpret data, drive goals and demand performance. He/she must not only have a good understanding of corporate strategy, but must also develop business managers through mentoring, thus ensuring that the people reporting to them are successful. At the same time, the group manager must be able to take hard objective decisions based on analysis, while maintaining good relationships and inspiring direct report managers.

If this level gets clogged because group executives are not prepared to give support and coach, the effect is that business managers usurp the role of functional managers. This affects everyone along the line and pushes every manager down one level in the pipeline (Charan et al. 2001: 100).

\subsubsection{The Leadership Pipeline Model: Managing the Enterprise}

As the leader of an enterprise, the main focus of this manager will be setting the direction for the entire enterprise. This requires him/her not only to be a long-term visionary thinker, but also to be able to drive performance in tune with the overall strategy (Charan et al. 200I: II7). The thinking preference that is required evaluating global issues (outward perspective) as well as evaluating local issues within the company (inward perspective), of the enterprise. Enterprise managers should be able to pay attention to global problems that could affect the enterprise, while at the same time evaluate the impact that the enterprise might have on global issues. They should be able to make sound judgements in this regard in a pro-active manner.

The enterprise manager must also have the 'softer thinking skills' ability to engage with stakeholders and to release the energy necessary to inspire the entire employee population through communication. At the same time, he/she must be able to drive the hard core business processes to deliver bottom-line results, leaving no room for errors (Charan et al. 200I: II8-120). In short, he/she must initiate, maintain, manage and inspire the process.

When CEOs are appointed, and they have skipped levels within the leadership pipeline, they often diminish the performance of managers - not only that of the direct reports, but of individuals all the way down the line. Charan et al., $(2001: 25)$ maintain that when the leadership pipeline becomes clogged at the top, it negatively impacts on all levels of leadership. 
4 Challenges for libraries in the digital age

A great deal has been written about the library in the digital age, largely from a perspective of information technology. Information technology changed the whole working paradigm over the past decades, as Stille (2002: 262) remarks:

If being a librarian once meant filing and retrieving books, it now means operating immensely complicated and expensive information systems, combining knowledge of traditional books and microfilm with that of computers, fibre-optic cables, server networks, elaborate software formats, audio-visual systems, among many other things.

We live in an information rich and information-driven world where access to information is key. According to Nicholas and Rowlands (2008: 3),

the digital consumer is now King, and communication and delivery channels that have opened up are the Kings' Horses but you would hardly know this from the responses of many information professionals.

The internet has moved into all corners of our life and online searching has become daily practice. Social networks like Facebook, MySpace, Linkedln, are choices for millions of people offering information. Google transformed the information landscape. Encyclopaedias are no longer considered the means to finding what you want. Instead, connected consumers are empowered to find information, and they think what they find in Wikipedia represents the "wisdoms of crowds" (Nicholas \& Rowlands 2008: 7I). All of this implies that the majority of library professionals "require a new mindset" (Nicholas \& Rowlands 2008: 2I3).

In cyberspace, every source seems as authoritative as the other; libraries are no longer the dominant players or the suppliers of information as first choice. Meeting the needs of the digital user who is already well connected through social media such as Facebook, Linkedln, MySpace and Twitter is not easy, and Nicholas and Rowlands (2008: 4) suggest that library professionals should think about their customers' needs in an entirely different way. This is key to delivering the right service.

We need to think innovatively and our thinking needs to be directed at what is going to be relevant to the user in the information age. It is only through vision and strategy that we will maintain a sense of purpose for the library in the digital age. Nicholas and Rowlands (2008: 3) admit that,

[c]onnected consumers now have access at any time of the day or night, through multiple devices and platforms, to all aspects of their information needs. If the traditional 'gatekeeper' is not there (at best) or gets in the way of this communication (at worst), consumers will abandon them to go their own way.

The rapid changes in the virtual world require library leaders to abandon the old school of thought pertaining to library use, users and information seeking that they acquired over the years. By proactively staying informed of what the digital users' needs are and what activities take place in the virtual space, library leaders need to shift their thinking. They should embark on futuristic and innovative strategies to not only find ways of keeping abreast of the constantly changing environment, but also be flexible enough to find alternative solutions for implementing the change. Taking up the challenges of the digital age while understanding and accommodating digital users is key. Failure to do so will result in a 'meltdown' of libraries, the signs of which (as claimed by Nicholas and Rowlands (2008:4)) are already there for all to see. Library leaders need to be alert and understand the technical changes that have taken place in the virtual information space. Hence they have to be ready to implement new strategies appropriate to being a centre of excellence for the production and dissemination of knowledge, and constituting a place of dialogue and understanding between cultures and people.

In Chapter 9 (Where do we go from here?) Nicholas and Rowlands (2008: 213 ) summarise the situation as follows:

"[...] there are not that many ways out of the current situation - between a rock (Google) and a hard place (the e-shopper). On the other hand, with so few solutions on offer they should be easy to remember and, hopefully, easier to achieve, especially as they require very little in the way of resources. In most cases, they simply require a new mindset."

SA Jnl Libs \& Info Sci 2012, 78(2) 


\section{Empirical study}

Based on the findings of Coffield's research (Coffield et al. 2004), which identified the Herrmann Brain Dominance Instrument ${ }^{\circledR}\left(\mathrm{HBDI}{ }^{\circledR}\right)$ as one of the six recommended models of learning styles, the instrument was selected for this project. The $\mathrm{HBDI}{ }^{\circledR}$ not only measures strong preferences of thinking for specific modes, but the added value lies in the fact that the profile highlights a low - or what Herrmann calls an avoidance - preference for a specific thinking mode as well. The latter is perhaps the most significant requirement for success in a particular career (Coffield et al. 2004: 77).

The $\mathrm{HBDI}^{\circledR}$ is a survey consisting of $\mathrm{I} 20$ items, based on 35 years of extensive research on brain dominance with over three million profiles in the Herrmann database worldwide. It is an assessment tool that quantifies thinking style preferences for each of the four modes. It displays the mental preferences of the individual but does not report on ability or competence. The results are displayed on a four-quadrant grid that emulates the four principal thinking structures in the brain as illustrated in Figures I to 5 .

All I 20 candidates selected for the six Carnegie Library Leadership Academies completed the online assessment and all received feedback on their individual profiles during a one-day intervention debriefing the content. The aim was to determine the thinking preferences of the individuals as well as the group, and to link the results to the thinking requirements of the leadership pipeline and positions candidates will be holding in the future. The assessment also evaluated possible areas that can be addressed, be it through coaching, mentoring or development programmes.

Knowledge of one's preferred thinking styles can be helpful in understanding the degree of comfort experienced in utilising one's strength on the one hand, and, on the other, understanding the degree of discomfort experienced in areas of avoidance or lesser preferred modes. Preference and avoidance are equally significant. Not being able to stretch beyond our comfort zones can have a severe influence on both professional and personal life.

\subsection{Analysis of results}

The data collected from the six groups was combined and will be discussed for the combined group as a whole. We created a group average, and this is expressed as a generic profile in the form of preference for the A-, B-, C-, and Dquadrants, where I = strong thinking preference, 2 = lesser preference signifying comfortable usage when the situation requires, and $3=$ potential avoidance of the particular quadrant thinking. The composite profile of the group (a map with superimposed individual profiles) as well as a preference map of the group is illustrated in Figure 7.

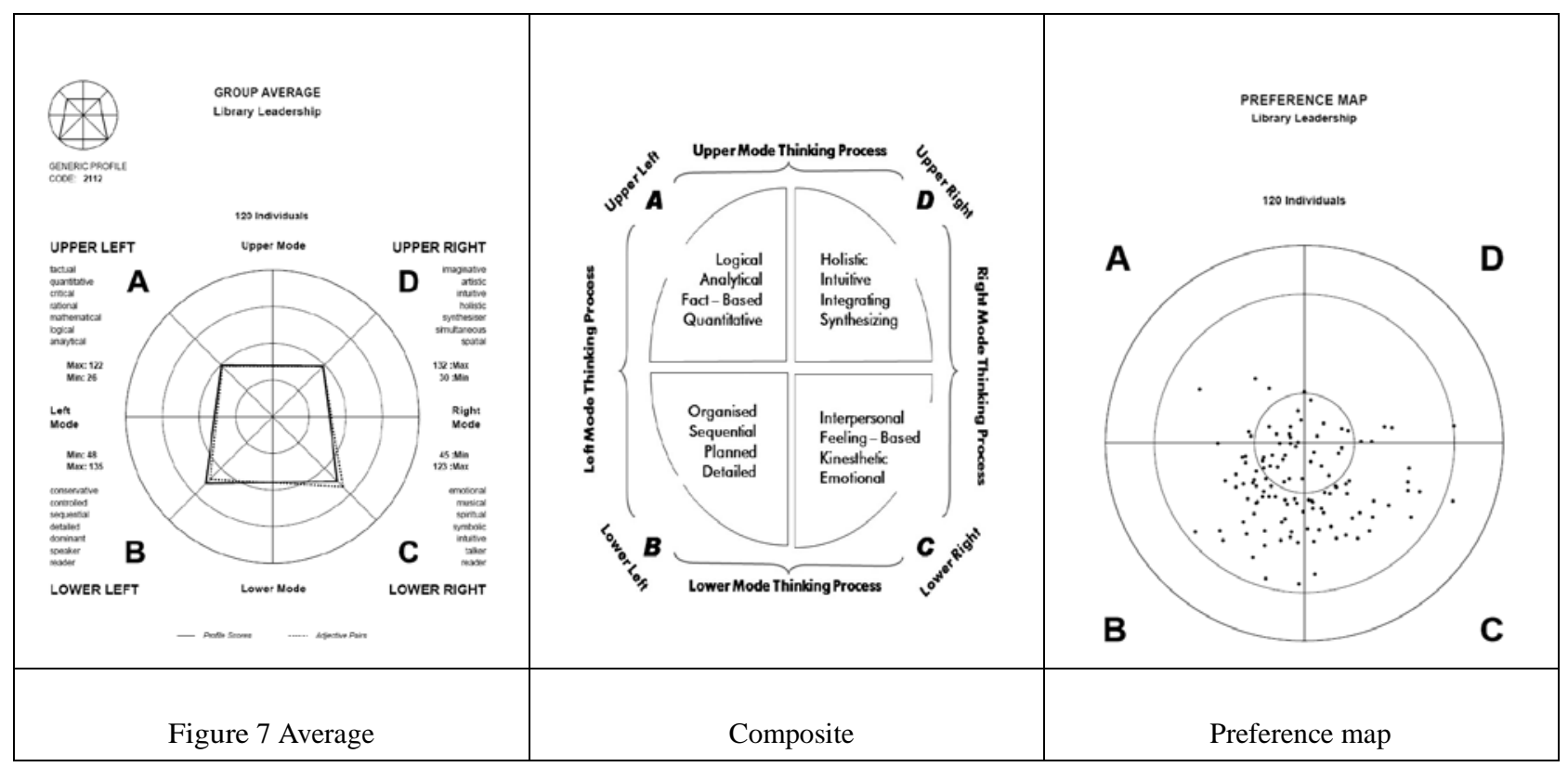

The generic profile of this team is significant in that it indicates a double dominance 2112 preference. The double dominant primary is for the B- and C-quadrant modes of thinking. The B-quadrant typically represents characteristics that include being in control, playing it safe, planning things first, getting things done, attending to detail, structuring tasks in a sequence, providing support and keeping administrative tasks up to date. This profile also indicates a strong preference for the C-quadrant, which indicates a preference for people, working in groups or teams, building relationships, engaging with others on a personal level rather than by e-mail, being part of a team, coaching and 
supporting others. The composite profile (all 120 profiles put on top of one another) confirms the fact that there is a strong preference for the $\mathrm{B}$ - and $\mathrm{C}$-quadrant thinking.

From the preference map it is important to note that the least preferred modes are for the A- and D-quadrant thinking. With regard to the A-quadrant, this implies that the group is less comfortable analysing data, logical processing, applying formulas, solving problems in logical ways, challenging decisions and results, taking up financial planning and responsibilities, being challenged on areas outside their field of expertise and working with technology. For the Dquadrant, this implies that the group is less comfortable generating alternatives, taking risks, inventing innovative solutions, providing vision, creating experimenting opportunities, selling their ideas, embracing change, looking at the big picture and seeing the end already from the beginning.

In analysing the individual results, only three participants from 120 had a strong preference $(100+)$ for A-quadrant thinking, representing $2,5 \%$ of the group. Two of the 120 participants had a strong preference $(100+)$ for the $D$ quadrant, thus I, $6 \%$ of the group. The majority of participants, 25 out of $120(20,8 \%)$, had a strong preference $(100+)$ for the B-quadrant, while 23 out of $120(19,1 \%)$ had a strong preference $(100+)$ for the C-quadrant.

\subsection{Implications of results}

Linking the thinking preferences of future library leaders in South Africa to the Leadership Pipeline as well as to the leadership traits and competencies outlined in this paper, it becomes evident that we need to keep embracing the dominant C-quadrant thinking identified, but at the same time we have to let go of the dominant B-quadrant way of thinking and doing things.

The emphasis should be on developing stronger A- and D-quadrant thinking preferences and competencies in the younger generation if we want to ensure that we develop library leaders who are knowledgeable about the latest technologies, comfortable to inspire and drive the organisational vision, and able to see the big picture.

The following is evident from our research: we need to develop Whole Brain ${ }^{\circledR}$ leadership programmes that focus on developing thinking skills as well as providing opportunities to unlearn activities that brought past success (Riggs 200I:10). At the core the programme should comprise Drotter's Leadership Pipeline model and Herrmann's Whole Brain ${ }^{\circledR}$ model, and include the traits and competencies identified by researchers as important in giving direction to what thinking skills need to be developed, for which level, to make a successful transition to the next level. Through a development programme, future leaders can be sensitised to using thinking requirements that were previously ignored (Charan et al., 200I: 17).

The programme should therefore provide for:

Developing A-quadrant thinking:

- Obtaining knowledge about technology to empower library professionals in the digital age

- Applying appropriate technology in a proactive and innovative way

- Cultivating high-order reasoning skills

- Acquiring skills to analyse and manipulate data in a logic way

- Developing decision-making skills based on facts

Developing D-quadrant thinking:

- Nurturing techniques to 'see' and 'read' the future

- Creating and driving the organisational vision

- Leading change

- Tolerating ambiguity

- Finding ways to inspire others

- Applying creative thinking

- Innovating with new technologies and projects

- Providing exposure to global issues, perspectives and thinking

Developing C-quadrant thinking:

- Creating self-awareness and self-regulated skills

- Mentoring and coaching others for better performance

- Creating and sustaining a positive working environment

- Motivating the work force

- Collaborating cross-functionally

SA Jnl Libs \& Info Sci 20I2, 78(2) 


\section{Recommendations}

In order to make the mental shift required for the digital age and be ready to take up the leadership responsibilities for the future, we recommend the following innovative options to be included in a library leadership development programme:

- Understanding thinking preference and areas of personal development comes before developing and changing thinking in the direction that would be appropriate for the leadership position for which an individual is responsible. Information with regard to thinking preferences has proven valuable. It can help individuals with personal as well as leadership growth opportunities.

- By expanding their thinking skills, leaders will be empowered and equipped with the necessary thinking tools that will enable them to make smooth transitions to every next level of the leadership pipeline in their organisations and throughout their career.

- Understanding the thinking requirements pertaining to the different levels of Drotter's Leadership pipeline is essential to prevent clogging of the pipeline. According to Hermann (1996: 102), it is often one's own preferences that lead to the clogging, as one would naturally want to revert to one's comfort zone and emphasise one's own preferences. The willingness of the leader to stretch and develop his/her thinking skills in all four quadrants will ultimately determine whether the leadership pipeline can be successfully unblocked.

- Certain quadrants in the Whole Brain ${ }^{\circledR}$ model are more dominant during certain stages. The higher one moves up in the pipeline, the greater the need for analytical skills (A-quadrant), strategic innovation skills (D-quadrant) and skills to motivate others ( $C$-quadrant), and the smaller the need for controlled (B-quadrant) thinking.

- Individuals who strive to utilise the thinking style most appropriate for the situation, have greater flexibility and creativity and are more effective problem solvers.

- Both the Leadership Pipeline and Herrmann Brain Dominance Instrument $\left(\mathrm{HBDI}{ }^{\circledR}\right)$ are useful tools in growing library leaders. Individuals are coached and mentored to make the mental shift and acquire the skills necessary to operate effectively at the next level of promotion.

- Applying Herrmann's Whole Brain ${ }^{\circledR}$ model and the Herrmann Brain Dominance Instrument $\left(\mathrm{HBDI}{ }^{\circledR}\right.$ ) as coaching tools can assist managers to develop thinking skills in less preferred modes and to make a success of the transition to every next level of the Leadership Pipeline model.

\section{Conclusion}

This article aimed to create an awareness of different thinking requirements for different levels of leadership positions. The Whole Brain ${ }^{\circledR}$ model and the Herrmann Brain Dominance Instrument ${ }^{\circledR}$ can serve as a model and a tool respectively to understand oneself and others better. Through coaching, mentoring and development programmes, individuals can develop thinking skills required for specific roles to which they are assigned and not become prisoners of their own thinking style preferences.

As additional research is conducted and shared in the professional library science literature, more librarians and library administrators should begin to employ thinking style research for both personal and organisational growth. Benfari (1995) created a four-step action plan to alter skills for effective personal growth. The steps are:

- Reflect: Take time to understand yourself and your co-workers in terms of strengths and weaknesses concerning thinking preferences and the organisation's culture.

- Identify: Find work situations in which you have been effective and those in which you have been ineffective.

- Determine: Recognise what role your thinking style plays in both the positive and negative outcomes in these situations.

- Modify: Work towards achieving positive outcomes at all times by using the thinking style most appropriate for the situation, and try to align these outcomes with the mission of the organisation.

\section{References}

Ammons-Stephens, S., Cole, H.J., Jenkins-Gibbs, K., Riehle, C.F. \& Weare, W.H. 2009. Developing core leadership competencies for the library profession. Journal for Library Leadership and Management, 23(2):63-74.

Benfari, R.C. 1995. Changing your management style: How to evaluate and improve your own performance. New York: Lexington Books.

Charan, R., Drotter, S. \& Noel, J. 200I. The leadership pipeline: how to build the leadership-powered company. San Francisco: John Wiley \& Sons.

Drotter, S. 2003. The leadership pipeline: the right leader in the right job. Management Forum Series. October 22. Salem, Oregon.

Hernon, P., Powell, R.R. \& Young, A.P. 200I. University library directors in the association of research libraries: the next generation, Part One. College and Research Libraries, 62(2): I I6-I46.

Hernon, P., Powell, R.R. \& Young, A.P. 2002. University library directors in the association of research libraries: the next generation, Part Two. College and Research Libraries, 63(I):73-90. 
Hernon, P., Powell, R.R. \& Young, A.P. 2003. The next library leadership: attributes of academic and public library directors. Westport, CT: Libraries Unlimited.

Hernon, P. \& Rossiter, N. 2006. Emotional intelligence: which traits are most prized? College and Research Libraries, 67(3):260275.

Herrmann, N. (Ed.). 1995. The Creative brain. $2^{\text {nd }}$ edition. USA: Quebecor Printing Book Group.

Herrmann, N. 1996. The Whole Brain Business Book. New York: McGraw-Hill.

Hopper, R. 2005. Emotional intelligence in academic library leadership. Library Staff Publications. Paper I. [Online]. http:// scholarsarchive.jwu.edu/staff_pub/I Accessed 5 April 2012.

Kurz, R. \& Bartram, D. 2002. Competency and individual performance: modelling the world of work. In I.T. Robertson, M. Callinan and D. Bartram (eds). 2002. Organizational Effectiveness: The Role of Psychology. Chichester, UK: Wiley, pp. $234-35$.

Lumsdaine, M. \& Lumsdaine, E.E. 1995. Creative problem solving - thinking skills for a changing world. Singapore: McGraw-Hill.

Lynch, B.P. 1988. Changes in library organizations. In A. Woodsworth and B. Von Wahlde. (eds). Leadership for Research Libraries: A Festschrift for Robert M. Hayes. Metuchen, NJ: Scarecrow Press, pp. 67-77.

Nicholas, D. \& Rowlands, I. 2008. Digital consumers reshaping the information profession. London: Facet Publishing.

Riggs, D.E. 1998. Visionary leadership. In T.F. Mech and G.B. McCabe (Eds.). 1998. Leadership and Academic Librarians. Westport, CT: Greenwood, pp. 55-65.

Riggs, D.E. 200I. The crisis and opportunities in library leadership. In M.D. Winston (ed.) Leadership in the Library and Information Science Professions: Theory and Practice. New York: Haworth, pp. 5- 17.

Stille, A. 2002. The future of the past. Picador.

UPLS. 2008. University of Pretoria receives grant to develop library skills and leadership. [Online]. http://www.library.up.ac.za/ carnegie/carnegie.htm Accessed 2 April 2012. 